\title{
Persistence of Fecal Indicators and Microbial Source Tracking Markers in Water Flushed from Riverbank Soils
}

\author{
Jose S. Calderon • Matthew E. Verbyla $\cdot$ Mia Gil $\cdot$ \\ Federick Pinongcos $\cdot$ Alicia M. Kinoshita $\cdot$ \\ Natalie Mladenov (1)
}

Received: 5 October 2021 / Accepted: 3 February 2022 / Published online: 26 February 2022

(C) The Author(s) 2022

\begin{abstract}
Sewer overflows and exfiltration can potentially contaminate water bodies with pathogens from wastewater. Microbial source tracking (MST) methods such as the detection of the HF183 gene target of Bacteroides have been proposed to monitor human fecal pollution inputs to surface waters; however, the persistence of HF183 and other MST markers in water flushed from soils after contamination events is not well understood. In this study, the persistence and decay of two culture-based fecal indicators, Escherichia coli and enterococci, and two molecular MST markers, HF183 and pepper mild mottle virus (PMMoV), were evaluated in riverbank soils spiked with untreated sewage, which were left idle for 1, 14, 28, 60, and 121 days under dark conditions and then flushed with synthetic rainwater. All four microbial indicators were still detected in flush water 4 months after the soil was contaminated. PMMoV persisted much longer and had a slower decay rate than the other microbial indicators, and E. coli degraded most rapidly. In consecutive flushing experiments with
\end{abstract}

Supplementary Information The online version contains supplementary material available at https://doi. org/10.1007/s11270-022-05542-8.

J. S. Calderon · M. E. Verbyla · M. Gil · F. Pinongcos ·

A. M. Kinoshita $\cdot$ N. Mladenov $(\square)$

Department of Civil, Construction, and Environmental

Engineering, San Diego State University, San Diego,

CA 92182, USA

e-mail: nmladenov@sdsu.edu fresh (1 day) sewage-spiked soils, HF183, E. coli, and enterococci were all detected after 20 consecutive flushes with rainwater, but PMMoV was not detected after the fifth flush. Our findings indicate that water (e.g., stormwater interflow) flushing through riverbank soils that have previously been contaminated by sewer overflows or sewer exfiltration can potentially be a source of microbial pollution to surface waters, even for several months after the contamination occurs. Results from this study also demonstrate the benefits of using multiple human-associated fecal indicators to distinguish pollution from different microbial groups in water bodies.

Keywords Microbial source tracking - HF183 . PMMoV $\cdot$ Non-point source $\cdot$ Sanitary sewer overflow $\cdot$ Sewer exfiltration

\section{Introduction}

Human-associated fecal contaminants and pathogens have been detected in rivers during storm events (Schiff et al., 2016), and fecal contamination to ocean water from river outfalls after rain events has been associated with increased rates of gastrointestinal illness and multiple infections amongst surfers (Arnold et al., 2017). Microbial source tracking (MST) methods such as the detection of the HF183 gene target of Bacteroides are increasingly being used to monitor human fecal pollution in surface waters (US EPA, 
2019), but the use of these markers by themselves are not sufficient to separate out the relative contributions of different sources of human fecal pollution, especially from non-point sources. Non-point sources of human fecal pollution to surface waters include leaky sanitary sewers (exfiltration), runoff from open defecation, septic system leach fields, sanitary and combined sewer overflows, and unknown pollution inputs to some municipal storm sewer systems.

Sanitary sewer overflows (SSOs) introduce untreated wastewater to nearby soils or waterways during both wet and dry weather (Baresel \& Olshammer, 2019). Sanitary sewer overflow events are quite common, potentially resulting from storms that could be classified as annual storm frequency events across all durations (Day \& Seay, 2020). The most recent reporting by the California State Water Resources Control Board (2015) lists a total of 4,580 SSOs in fiscal year 2014-2015, resulting in more than 11 million gallons of sewage reaching the environment, and there are likely at least 23,000 to 75,000 SSO events in the USA each year (ASCE, 2017). Sanitary sewer overflows have been associated with increases in emergency room visits for gastrointestinal illnesses, which tended to peak 10 to 14 days following the sewer overflow events (Jagai et al., 2017; Potera, 2018). Furthermore, multiple studies have predicted that climate change and urbanization cause significant increases in the occurrence, volume, and duration of sanitary and combined SSO events (Astaraie-Imani et al., 2012; Mahaut \& Andrieu, 2019; Tavakol-Davani et al., 2016). In addition to the implementation of efforts to reduce the frequency of sewer overflows and to monitor the frequency of their occurrence, there are needs to regulate or restrict access to sites impacted by SSOs in order to protect public health and, more specifically, to know how long access should be restricted. Traditional fecal indicator bacteria, such as E. coli and enterococci, do not strictly indicate human fecal pollution, while MST markers such as HF183 and pepper mild mottle virus (PMMoV) are more specific to human fecal pollution (Symonds et al., 2018). However, molecular methods such as qPCR and RT-qPCR, which are used to detect HF183 and PMMoV, respectively, do not provide information about viability and may pick up DNA and RNA from nonviable microorganisms. At the same time, viruses such as PMMoV may have different persistence in the environment than bacteria, such as E. coli, enterococci, and Bacteroides. As such, it is necessary to better understand the persistence of different types of microbial pollutants and pathogens in soils and sediments impacted by SSOs.

Sewer infrastructure also deteriorates over time due to structural failure, aging, and physical, biological, or chemical factors that contribute to deterioration of the pipe materials. In the USA, there are over 800,000 miles of public sewers and 500,000 miles of private laterals, much of which is in need of being replaced, according to a study by the American Society of Civil Engineers (ASCE, 2017). The ASCE gave wastewater collection and treatment infrastructure a grade of $\mathrm{D}+$, which means that the infrastructure is in "fair to poor condition and mostly below standard, with many elements approaching the end of their service life" (ASCE, 2017). A study done by the US Environmental Protection Agency (Amick \& Burgess, 2000) concluded that the risk of sewer exfiltration was probably limited to US cities with deeper groundwater, mainly located west of the Mississippi River and along the Appalachian Mountains. Measurements done in the late 1980s showed exfiltration rates that ranged from 5,000 to more than 50,000 gallons per inch diameter per mile per day, accounting for $12-30 \%$ of the total flow in the pipes (US EPA, 1989). In other locations throughout the world, exfiltration rates may be significantly higher-for example, sewer exfiltration was measured to account for $74 \%$ of the sewage inflow during the dry season in Hue, Vietnam (Watanabe et al., 2019). Sewer exfiltration also is responsible for the introduction of nutrients, pathogens (Reynolds \& Barrett, 2003; Rutsch et al., 2008; Gotkowitz et al., 2016; Roehrdanz et al., 2016), and chemical contaminants (Roehrdanz et al., 2016), including pharmaceuticals and personal care products, into shallow groundwater (Chisala \& Lerner, 2008) or into the vadose zone, from which baseflow or interflow of stormwater (Pinongcos, 2020; Mladenov et al., 2020) may transport these contaminants into waterways. Viruses in particular can travel long distances through the subsurface compared to larger bacteria and protozoa (Hunt \& Johnson, 2017; Schijven et al., 2017), and relationships between sewer age and the detection of enteric viruses in groundwater below sanitary sewers has been reported (Bradbury et al., 2013; Gotkowitz et al., 2016). Due to their prevalence in wastewater and persistence in water matrices, novel viral markers, such as PMMoV, have been proposed as viral water quality monitoring tools (Bivins et al., 2020). 
In June 2019, the San Diego Regional Water Quality Control Board (2019) issued an investigative order to identify and quantify the sources and transport pathways of human fecal pollution to the San Diego River, identifying possible sources to include SSOs, discharges and exfiltration from sewer collection systems and laterals, discharges from on-site wastewater treatment systems, illicit connections and discharges to stormwater infrastructure, and runoff mobilizing waste associated with homeless encampments. However, the relative contributions of each of these sources is unknown.

Leakages from sewer infrastructure in the form of sanitary or combined sewer overflows and sewer exfiltration result in the seepage of pathogenic bacteria, viruses, protozoa, and other microorganisms as well as organic carbon and nutrients into adjacent soils, where they may remain until a future rain event. These microorganisms and sewagederived constituents may remain in soils for long periods, especially in arid Mediterranean climates, where $>80 \%$ of the precipitation is constrained to the wet winter season (Aschmann, 1973).

This study seeks to evaluate the persistence of fecal indicator bacteria and microbial markers of human contamination in water flushed through soil under two conditions: (1) after multiple flushing events (referred to as the "flushing treatment") that simulate stormwater flushing contaminants from the soil surface or vadose zone via interflow and (2) after long-term drying and subsequent single flushing (referred to as the "decay treatment") that simulates the persistence of microbial indicators under these conditions during prolonged periods without stormwater flushing. Specifically, we measured the concentrations of Escherichia coli, fecal enterococci, the HF183 genetic marker (Bacteroides dorei), PMMoV, dissolved organic carbon (DOC), and total dissolved nitrogen (TDN) in flushed water with respect to the number of consecutive times the soil was flushed and with respect to the number of days the sewage-spiked soil was left to dry.

\section{Materials and Methods}

\subsection{Experimental Conditions}

Soil was collected at a distance of $\sim 10 \mathrm{~m}$ from the south side of Alvarado Creek (32.7778866,-117.0665544), which is a tributary of the San Diego River in San Diego, CA, USA. An area away from sewer manholes and known sewer lines and in between canopy with no anthropogenic debris was chosen, and the top $5 \mathrm{~cm}$ of the soil were scraped off with a sterilized scoopula to remove pebbles and large debris. Approximately $4 \mathrm{~kg}$ of soil was collected with sterilized scoopula from an area of $1,861 \mathrm{~cm}^{2}$, placed into a sterilized bag, and brought back to the laboratory. The soil was sieved through a 2-mm sieve and homogenized by hand on the same day of sample collection and stored in a desiccator prior to use. A portion of soil was analyzed for organic content using the loss on ignition method (Beaudoin, 2003). The organic matter content of the soil was determined to be $6.9 \%$, and soil sieve analysis indicated that the soil sample was $10.4 \%$ gravel, $76.8 \%$ sand, and $12.8 \%$ fine sediment (by weight). Approximately $10 \mathrm{mg}$ of soil was dried in a drying oven at $105{ }^{\circ} \mathrm{C}$ and homogenized by hand with a sterile trowel before being placed into duplicate sterilized 50-mL centrifuge tubes. The depth of the soil in the centrifuge tubes was approximately 1 inch, and the mass of the soil in each tube was $10 \mathrm{mg}$. Although the soil was not autoclaved, it is possible that the use of the drying oven may have affected the viability of the natural microbial community in the soil.

Screened untreated wastewater for soil spiking was collected as a single grab sample from the San Elijo Water Reclamation Facility (Cardiff, CA, USA) during the morning of 29 May 2019 and stored at $4{ }^{\circ} \mathrm{C}$ until use. Within $24 \mathrm{~h}$ of collection of the wastewater, two experiments were initiated, (1) a "consecutive flushing experiment" (Fig. 1a), meant to simulate flushing of sewage-contaminated soils during storm events, and (2) a "time-delay flushing experiment," meant to simulate the flushing of soils that had been previously contaminated by sewage and flushed by a rainfall event occurring after long periods of drying (14 days, 28 days, 60 days, and 121 days). Experiments were conducted in duplicate, and controls for the experiments comprised duplicate soil samples that were not spiked with wastewater, but were subjected to flushing, settling, and decanting at the same time as the spiked samples. The supernatant of the experimental controls was analyzed for all parameters in the same manner as the spiked soil samples for the consecutive flushing experiment, with the only difference being that the controls were only flushed once on the first day of the experiment. 


\section{a) Consecutive flushing experiment}

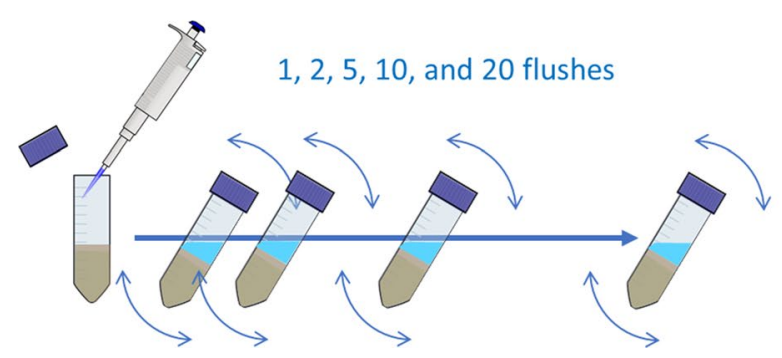

Fig. 1 Experimental simulations of a surface runoff or interflow flushing soils contaminated with untreated wastewater and b persistence and decay of microbial and chemical constituents

For both experiments, a single $5 \mathrm{~mL}$ aliquot of untreated wastewater (sewage) was pipetted into each of the centrifuge tubes, and this volume was sufficient to completely saturate the soil with untreated wastewater. The centrifuge tubes were then lightly capped to allow air to flow in and out of the tube, then placed inside a Class-II biosafety cabinet to dry at ambient temperature $\left(\sim 20{ }^{\circ} \mathrm{C}\right)$. After $24 \mathrm{~h}$ of spiking soils with wastewater, tubes were removed in duplicate and flushed once by adding $45 \mathrm{~mL}$ of autoclaved synthetic rainwater $\left(0.16 \mathrm{mM} \mathrm{CaCl}, 0.02 \mathrm{mM} \mathrm{Ca}\left(\mathrm{NO}_{3}\right)_{2}\right.$, and $0.12 \mathrm{mM} \mathrm{Na}_{2} \mathrm{SO}_{4} ; \mathrm{pH}=7.17, \mathrm{EC}=27.2 \mu \mathrm{S}$ in ultrapure water) (as per Smith et al., 2002) to the centrifuge tube. The tubes were turned twice using an end-over-end motion and then set aside to settle for $10 \mathrm{~min}$. Supernatant was then removed from each duplicate tube by careful pipetting. After this first flush, additional consecutive flushes of $45 \mathrm{~mL}$ each were performed for a total of 20 flushes ("consecutive flushing experiment"; Fig. 1a) of each duplicate tube. On average, $38 \mathrm{~mL}$ of supernatant was recovered from each flush, and recovery volumes ranged from 33 to $44 \mathrm{~mL}$. The decanted supernatants from the first, second, fifth, tenth, and twentieth flushes were reserved for chemical and microbial analyses. The remaining soil fractions were not analyzed, as we were more interested in quantifying pollutant loadings in the flushed water (e.g., the supernatant), as it was meant to simulate stormwater interflow that could potentially contaminate surface waters. For the "time-delay flushing experiment" (Fig. 1b), duplicate sample tubes containing $10 \mathrm{mg}$ of soil spiked with $5 \mathrm{~mL}$ of untreated wastewater were left loosely capped in the biosafety cabinet for $14,28,60$, and

\section{b) Time-delay flushing experiment}

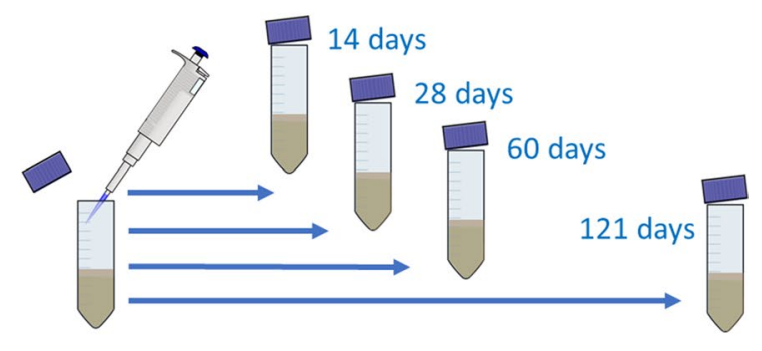

in water flushed from soils contaminated by untreated wastewater after being left idle for 14, 28, 60, and 121 days

121 days after spiking (a total of 8 tubes); then they were sampled destructively as follows: the duplicate tubes were each flushed once with $45 \mathrm{~mL}$ of sterile synthetic rainwater on the prescribed day, using the same end-over-end motion described previously, and the supernatants were collected for analysis.

\subsection{Quantification of Microbial Constituents}

All samples were analyzed for E. coli and enterococci on the same day of collection using the Colilert and Enterolert methods, respectively, with the IDEXX Quanti-Tray 2000 system, as described in Standard Methods 9223B (APHA, 2012). Samples were vortexed for $10 \mathrm{~s}$ at maximum speed between dilutions to attempt to dislodge suspended particles. Samples anticipated to have high concentrations were diluted serially, either ten-fold or 100-fold at a time, vortexing between serial dilutions, with a maximum dilution of up to $1: 10,000$, and the concentrations were corrected for the dilution factor. Samples with suspected low concentrations were analyzed with a dilution of 1:100, resulting in a limit of detection of 100 MPN/100 mL for both E. coli and enterococci.

Bacteria and viruses in samples were concentrated from volumes between 30 and $40 \mathrm{~mL}$, using membrane filtration and the adsorption-extraction method, respectively (Ahmed et al., 2015; Symonds et al., 2014; Verbyla et al., 2016). Briefly, $\mathrm{MgCl}_{2}$ was added to samples (final concentration of $25 \mathrm{mM}$ ), and the $\mathrm{pH}$ was adjusted to $3.0-3.5$ with $1.0 \mathrm{M}$ acetic acid. Then, samples were vacuum-filtered through 0.45$\mu \mathrm{m}, 47-\mathrm{mm}$ mixed cellulose ester filters (HAWP type, Millipore). Filters were placed into bead-beating 
tubes (lysis matrix E, MP Biomedical) with $600 \mu \mathrm{L}$ of lysis buffer from the AllPrep PowerViral RNA/ DNA Kit (Qiagen, Germantown, MD, USA) and 10\% $\beta$-mercaptoethanol, and vortexed at high speed for $10 \mathrm{~min}$. After centrifugation at 13,000 g for $1 \mathrm{~min}$, filter lysates (typically $\sim 500 \mu \mathrm{L}$ ) were then collected with a pipette and then transferred to clean microcentrifuge tubes, as described previously (Ahmed et al., 2015). Extracted nucleic acids were then purified using the AllPrep PowerViral RNA/DNA Kit, following the manufacturer's recommended protocols, with final elution in a volume of $50 \mu \mathrm{L}$ molecular grade water. Then, $8 \mu \mathrm{L}$ of the extracted and purified nucleic acids were reverse transcribed with random hexamers using the SuperScript IV First-Strand cDNA Synthesis System (Invitrogen), following the manufacturer's recommended protocol.

Molecular targets were quantified with the BioRad QX200 droplet digital polymerase chain reaction (ddPCR) system, in a $20 \mu \mathrm{L}$ reaction with 3 $\mu \mathrm{L}$ of purified DNA or $2 \mu \mathrm{L}$ of cDNA containing the ddPCR Supermix for Probes (Bio-Rad), as well as primers and probes for the HF183/BacR287 or PMMoV assays (Supplementary Information) at final concentrations of $900 \mathrm{nM}$ (primers) and $250 \mathrm{nM}$ (probes). Thermocycling conditions were set to $95{ }^{\circ} \mathrm{C}$ for $10 \mathrm{~min}$ followed by 40 cycles of $94{ }^{\circ} \mathrm{C}$ for $30 \mathrm{~s}$ and then $60{ }^{\circ} \mathrm{C}$ for $1 \mathrm{~min}$. After completion, samples were held at $98^{\circ} \mathrm{C}$ for $10 \mathrm{~min}$. The calculation of the assay limits of detection is described in detail in the Supplementary Information. Quality assurance and quality control recommendations were followed as described by Huggett et al. (2013) and are described in detail in the Supplementary Information.

Prior to spiking, a sample of the homogenized soil used for the experiments was analyzed for $E$. coli, enterococci, HF183, and PMMoV, using the methods described above, with the following differences: (1) E. coli and enterococci were eluted from $20 \mathrm{~g}$ of soil with $40 \mathrm{~mL}$ of DI water (Julian et al., 2015) by vortexing for $1 \mathrm{~min}$, the collecting the supernatant, which was diluted by a factor of 1:10 and analyzed using the IDEXX protocol, as described above; (2) nucleic acids for HF183 and PMMoV analysis were extracted directly from the soil using the RNeasy PowerSoil total RNA and DNA kits (Qiagen), following the manufacturer's recommendations. Neither E. coli, enterococci, HF183, nor PMMoV were detected in the unspiked soil. Concentrations of E. coli, enterococci, HF183, and $\mathrm{PMMoV}$ in the wastewater used for spiking were multiplied by the volume spiked $(5 \mathrm{~mL})$ to calculate microbial loadings in the spiked soil. Concentrations of E. coli, enterococci, HF183, and $\mathrm{PMMoV}$ in the flushed water were multiplied by the flush volume $(45 \mathrm{~mL})$ to calculate the microbial loadings from each flush. For example, if a concentration of $7.93 \times 10^{3} \mathrm{gc} / \mathrm{mL}$ of HF183 was detected in the flush water, then that concentration would be multiplied by the volume of water flushed through the sample $(45 \mathrm{~mL})$ to get the loading $\left(7.93 \times 10^{3}\right.$ $\mathrm{gc} / \mathrm{mL} \times 45 \mathrm{~mL}$ per flush $=3.57 \times 10^{5} \mathrm{gc}$ per flush).

\subsection{Quantification of Chemical Constituents}

All samples for DOC and TDN analysis were filtered through $0.7 \mu \mathrm{m}$ (nominal pore size) precombusted $\left(500{ }^{\circ} \mathrm{C}\right.$ for $\left.4 \mathrm{~h}\right)$ glass fiber filters and preserved immediately with hydrochloric acid. These samples were analyzed within 2 weeks of sample collection. Dissolved organic carbon (DOC) and total dissolved nitrogen (TDN) were measured (at a dilution of 1:20) using a Shimadzu TOC-L Total Organic Carbon Analyzer with a chemiluminescent nitrogen detector. The instrument uses a high temperature combustion method, which reports DOC concentrations as non-purgeable organic carbon. Each individual sample was analyzed with three sample injections. If the threshold for the coefficient of variation $(20 \%)$ was exceeded, the sample was run again until the $\mathrm{CV}$ met the threshold, and the mean of those results was reported. In addition, each sample was run in duplicate, and standard deviations were within $10 \%$ of the mean. DOC and TDN concentrations in sewage used for spiking were $59.4 \mathrm{mg} \mathrm{C} / \mathrm{L}$ and $88.7 \mathrm{mg} \mathrm{N} / \mathrm{L}$, respectively. When diluted with $45 \mathrm{~mL}$ of synthetic rainwater for flushing, this resulted in an additional $6.6 \mathrm{mg} \mathrm{C} / \mathrm{L}$ and $9.9 \mathrm{mg} \mathrm{N} / \mathrm{L}$ added to the $\mathrm{C}$ and $\mathrm{N}$ already in water flushed from unspiked soil.

\subsection{Statistical Analysis}

Changes in microbial loadings in rainwater flushed through sewage-spiked soils with respect to the number of flushes (i.e., volume of flushed water) were plotted and linear regression was performed. 
Differences in the rate of decrease in microbial loadings in rainwater flushed through sewage-spiked soils with respect to the number of days since contamination were assessed using analysis of covariance (ANCOVA) to test the equality of slopes for log-linear regression curves for pseudo-first-order decay. All statistical tests were performed at the alpha level of 0.05 using R v3.4.2 or Microsoft Excel.

\section{Results and Discussion}

\subsection{Concentrations of Chemical Constituents}

In the consecutive flushing experiment, concentrations of DOC and TDN in sewage-spiked soils had steep decreases, from $>80 \mathrm{mg} \mathrm{C} / \mathrm{L}$ and $\sim 8.0 \mathrm{mg} \mathrm{N} / \mathrm{L}$ for the first flush to $<10.0 \mathrm{mg} \mathrm{C} / \mathrm{L}$ and $<0.6 \mathrm{mg} \mathrm{N} / \mathrm{L}$ by the 5 th flush (Figs. $2 \mathrm{a}$ and $2 \mathrm{c}$ ). After the 5 th flush, DOC and TDN concentrations changed very little, with $<10 \%$ of the initial concentration remaining. The decrease in both DOC and TDN as a function of flushing volume (for the first 5-10 flushes) followed a decrease that appeared to be consistent with secondorder rate processes (Supplemental Figure S1 shows that relationships of $1 /$ concentration vs. flush volumes had $r^{2}$ values ranging from 0.98 to 0.999 ). This result reveals that the initial stages of wetting and flushing are most important for mobilizing carbon and nutrients from soils. Also, it is worth noting that controls (without sewage spiking) did also experience decreases in DOC and TDN concentration, which are naturally found in soils, but the starting concentrations were lower than in spiked soils, with $55 \mathrm{mg}$ $\mathrm{C} / \mathrm{L}$ and $3.7 \mathrm{mg} \mathrm{N} / \mathrm{L}$ measured in the first flush; therefore, the decrease in concentrations during the first 5 flushes was not as pronounced as in the spiked soil flushing experiments. For DOC, the second flush of the control soils only removed $6-9 \%$ of the initial DOC concentration (compared to $>70 \%$ removal in the spiked soils), and the 5th flush still had $>25 \%$ of the initial DOC concentration remaining. It is possible that sewage spiking increased the soil moisture (even though soils were left to dry for $24 \mathrm{~h}$ after spiking). This increased soil moisture may have "primed" soils for more facile and efficient flushing of solutes.

Results from the time-delay flushing experiment show variability in both DOC and TDN concentrations, which make it difficult to determine whether there is any degradation of either solute over longterm dry conditions. Due to destructive sampling for this experiment, each set of duplicate tubes did contain a new soil sub-sample (from the original homogenized soil sample), and some, even minor, amount of
Fig. 2 Concentrations of dissolved organic carbon (DOC; $\mathbf{a}$ and $\mathbf{b}$ ) and total dissolved nitrogen (TDN; c and d) for synthetic rainwater flushed through soils contaminated with sewage with respect to the number of consecutive flushes (a and c) and with respect to the number of days since the soils were contaminated (b and d); dashed lines in a and $\mathbf{c}$ show concentrations in controls without sewage spiking, and dashed lines in $\mathbf{b}$ and $\mathbf{d}$ show predicted concentrations for day 1 based on concentrations in unspiked soil and sewage used for spiking
Consecutive Flushing

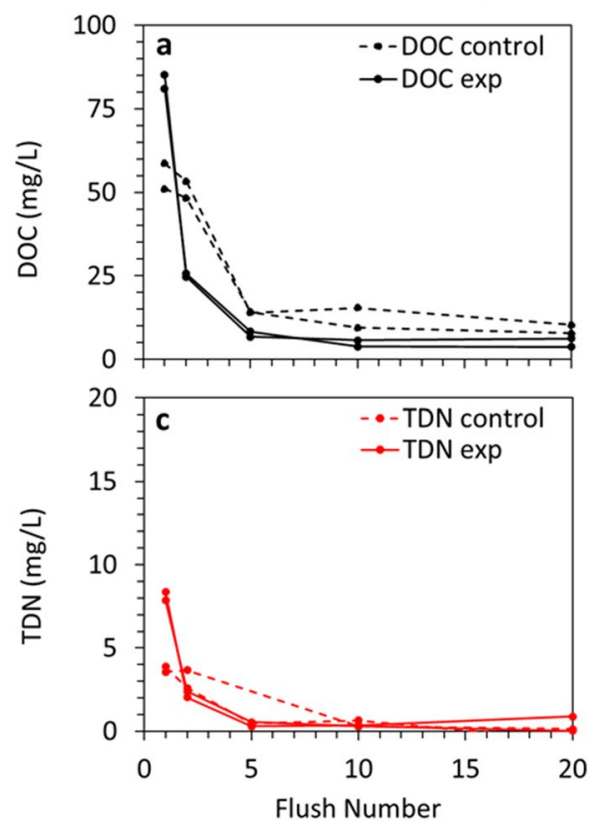

Time-delay Flushing
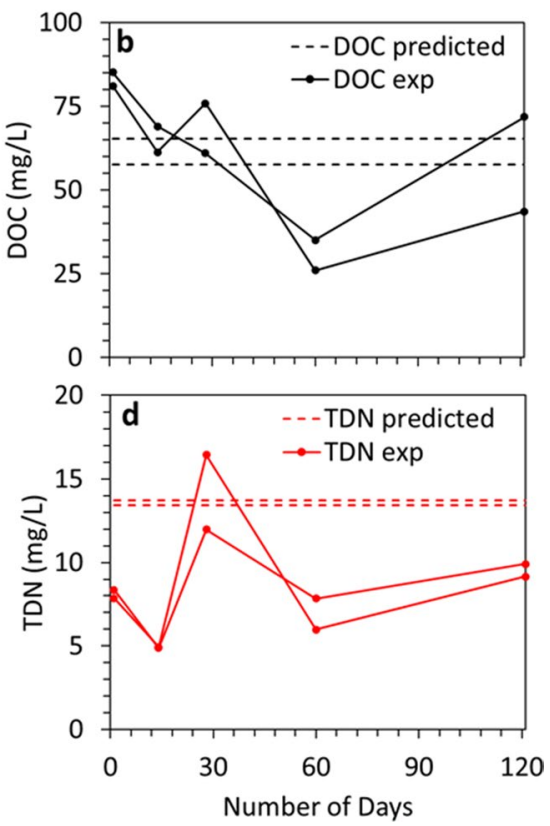
heterogeneity in the soil organic matter content may explain the variability in both DOC and TDN concentrations. The flushing experiment, by comparison, had all samples withdrawn from the same centrifuge tube, so no variability in concentrations is observed among flushes. Nonetheless, variable concentrations that sometime exceeded the predicted concentrations (from mass balance calculations) and the lack of a clear decreasing trend in DOC and TDN concentrations in the time-delay flushing experiment suggest that there was little decay of these solutes over time. This was not the case for microbial markers, as will be discussed next.

\subsection{Concentrations of Microbial Constituents}

The measured changes in the concentrations of microbial constituents with respect to each subsequent flush and with respect to the number of days since contamination are shown in Fig. 3. The concentrations in the sewage used to spike the soils were $2.2 \times 10^{7}$ MPN/100 mL for E. coli and $3.0 \times 10^{6} \mathrm{MPN} / 100 \mathrm{~mL}$ for enterococci, and $5 \mathrm{~mL}$ of sewage was spiked into the soil, which means that a total of $1.1 \times 10^{6} \mathrm{MPN} E$. coli and $1.5 \times 10^{5} \mathrm{MPN}$ enterococci were added to the soil on average (dashed lines in Fig. 3a and b). For the consecutive flushing experiment, the geometric mean initial concentrations of fecal indicator bacteria in the water from the first flush, one day after soils were spiked with sewage, were $5.5 \times 10^{7} \mathrm{MPN} / 100 \mathrm{~mL}$ and $3.4 \times 10^{6} \mathrm{MPN} / 100 \mathrm{~mL}$ for $E$. coli and enterococci, respectively. Based on these values, the loadings of $E$. coli and enterococci flushed away from the soil for flush 1 were both an order of magnitude greater than the loadings originally added. Given that E. coli and enterococci were not detected in duplicate flushes of the original, unspiked soil samples (both $<1000$ MPN/100 mL), it is possible that microbial growth may have occurred overnight. This finding of potential regrowth of both $E$. coli and enterococci in duplicate spiked sample tubes is important considering the extremely high FIB concentrations found in urban waterways (Hathaway \& Hunt, 2011). For example, FIB concentrations are regularly orders of magnitude higher during storm events than during baseflow in the San Diego River (Pinongcos, 2020). Therefore, regrowth upon soil wetting is an important additional consideration when trying to evaluate the elevated FIB concentrations.

Subsequent flushes yielded substantially lower loadings of E. coli and enterococci. Although loadings of all microbial markers tailed off by the end of
Fig. 3 Loadings (a and b) and $\log _{10}$ differences in the loadings (c and $\mathbf{d}$ ) for E. coli, fecal enterococci, HF183, and PMMoV for synthetic rainwater flushed through soils contaminated with sewage with respect to the number of consecutive flushes (a and c) and with respect to the number of days since the soils were contaminated (b and d); dashed lines show the loadings from the sewage spiked into the soil on day 1. Unspiked soils had no detectable concentrations of E. coli, enterococci, HF183, or PMMoV. Data from samples analyzed for $E$. coli after the 20th flush were non-detects because they were analyzed at too high of a dilution, so loadings were below 100,000 MPN per flush
Consecutive Flushing
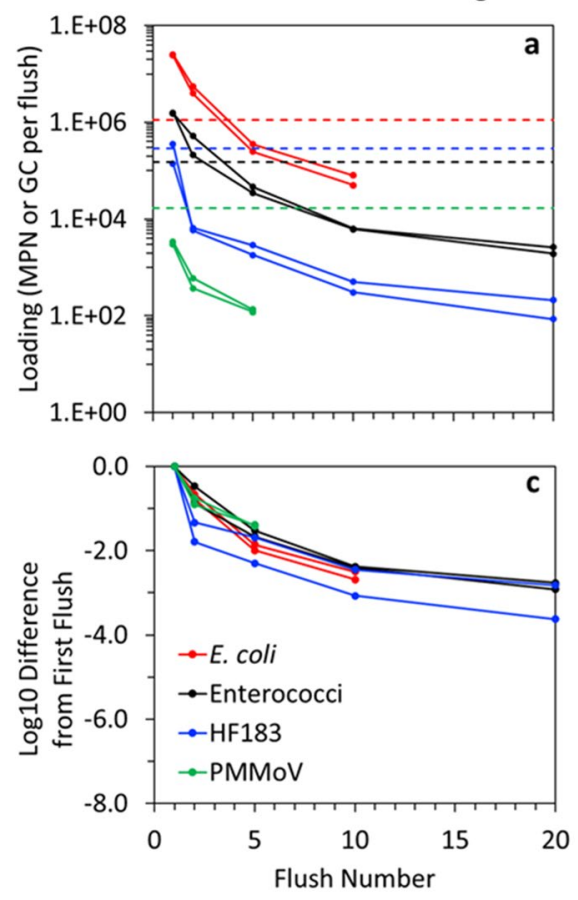

Time-delay Flushing
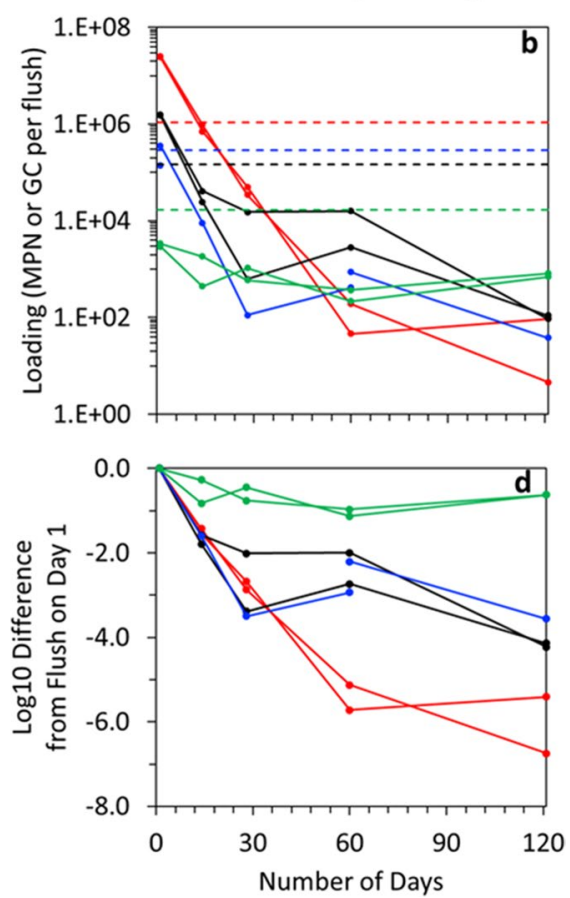
the experiment, there were still $2.3 \times 10^{3} \mathrm{MPN}$ of enterococci and $1.5 \times 10^{2} \mathrm{GC}$ of HF183 detected in the supernatant $(45 \mathrm{~mL})$ of the 20 th consecutive flush. The dilution (1:1000) used for enumerating $E$. coli in the supernatant of the 20th flush was too high and resulted in no detection; therefore, the final concentrations of $E$. coli were below the limit of detection $(<1000$ MPN/100 mL) for both replicates. The rapid decrease in microbial loadings of all markers between the first flush and the 5th flush approached a $2-\log _{10}(99 \%)$ difference, which is an order of magnitude greater than for DOC and TDN (>90\% by the 5th flush). This result also supports that the early stages of wetting and flushing are probably most important for mobilizing both microorganisms and solutes from soils.

As was the case for $E$. coli and enterococci, neither HF183 nor PMMoV were detected in the original, unspiked soil samples. On the other hand, concentrations of HF183 and PMMoV in the sewage used to spike the soils were $5.9 \times 10^{6} \mathrm{gc} / 100 \mathrm{~mL}$ and $3.4 \times 10^{5} \mathrm{gc} / 100 \mathrm{~mL}$, respectively. Given that the soils were each spiked with $5 \mathrm{~mL}$ of sewage, the total numbers of HF183 and PMMoV added to the soils were approximately $2.9 \times 10^{5}$ and $1.7 \times 10^{4}$ gene copies, respectively, in both experiments (dashed lines in Fig. $3 \mathrm{a}$ and $\mathrm{b}$ ). The geometric mean initial concentrations of HF183 and PMMoV in the water from the first flush, one day after soils were spiked with sewage, were $5.0 \times 10^{5} \mathrm{MPN} / 100 \mathrm{~mL}$ and $7.0 \times 10^{3}$ MPN/100 mL, respectively. Subsequent flushes yielded substantially lower loadings of HF183 and PMMoV, which tailed off with a similar pattern to $E$. coli and enterococci (Fig. 3c). Interestingly, PMMoV was not detected after the 10th flush, which may be due to the lower starting concentration of PMMoV in the sewage used to spike the soils. Moreover, the smaller size of viruses compared to bacteria has an important influence on their mobility (Hunt \& Johnson, 2017), which may result in the faster flushing of PMMoV compared to the bacterial markers.

The retention, sorption, and desorption of fecal bacteria by soil have been previously studied (Jamieson et al., 2002; Stevik et al., 2004). Henry and Dillaha (2004) reported that $78 \%$ of E. coli sorbed to topsoil within $1 \mathrm{~h}$, and Mankin et al. (2007) reported that the sorption of E. coli to soil was reversible and dependent on the soil type-nearly $100 \%$ of $E$. coli desorbed from sandy soil with one flush, but less than $15 \%$ desorbed from topsoil after three flushes. We observed much higher quantities of $E$. coli and enterococci in the first and second flush relative to the number of bacteria added to the soil, indicating possible regrowth, which is consistent with previous studies, according to a review article (Jamieson et al., 2002). We also found that the quantity of bacteria in the second and fifth flushes was more than $25 \%$ of the quantity flushed away initially (in the first flush), potentially indicating that the desorption of fecal bacteria from certain riverbank soils may be a prolonged process.

With respect to the number of days after contamination until the soils were flushed (time-delay flushing experiment), the different microbial markers underwent attenuation over the 121-day experiment, which may be due to decay in the soil or sorption of microorganisms to the soils. The attenuation of microorganisms, as indicated by the $\log 10$ difference in microbial concentrations, ranged from $\sim 1-\log$ for PMMoV ( $~ 90 \%$ reduction) to $\sim 6-\log (99.9999 \%$ reduction) for $E$. coli over the 121-day experimental period (Fig. 3d). Wastewater-spiked soils continued to leach detectable concentrations of $E$. coli, enterococci, HF183, and PMMoV, even after 4 months. In the case of $E$. coli, previous studies have shown its persistence and survival in soils (Brennan et al., 2010b), which was attributed to an advantageous physiology that favors the soil environment (Brennan et al., 2010a). Similarly, E. coli, enterococci, and HF183 were found to persist in sewage-inoculated sediments kept over a 21-day period, but PMMoV was not studied (Zimmer-Faust et al., 2017).

There were also substantial differences in the loadings for the different microbial groups (Fig. $3 \mathrm{~b}$ and d), indicating differences in the persistence of these microbes or the related gene targets in contaminated soils. For instance, the loading of $E$. coli was highest in the flush that occurred one day after contamination (its concentration in sewage was also the highest). However, in the flush performed 4 months after contamination, the loading of $E$. coli in the flushed water was the lowest, indicating that it likely decayed faster than the rest of the microorganisms. By contrast, PMMoV had the lowest loadings in flush water on the first day but had the highest loading in the flush water after 4 months. The attenuation rate for $E$. coli was higher than the attenuation rates for HF183 and enterococci, which were higher than the attenuation rate for PMMoV. It is important to note that PMMoV and HF183 were measured using ddPCR, while E. coli 
and enterococci were measured using culture-based methods, so the gene targets detected for HF183 and PMMoV did not necessarily come from viable microorganisms. Also, it is important to note that we did not directly measure microbial decay, since the decrease in concentrations after different idle times could have been a result of bacterial die-off or irreversible adsorption.

The attenuation rates appeared to follow firstorder kinetics for the first month or two, with possible subsequent decelerating attenuation rates (tailing effect). Assuming a first order decrease for the first month only, the pseudo-first-order attenuation rate coefficients (calculated on a natural log basis) were $0.103 \mathrm{day}^{-1}$ for E. coli, $0.100 \mathrm{day}^{-1}$ for enterococci, $0.121 \mathrm{day}^{-1}$ for HF183, and $0.022 \mathrm{day}^{-1}$ for PMMoV. This equates to $\mathrm{T}_{90}$ values of $\sim 10$ days and $\mathrm{T}_{99}$ values of 20 days for E. coli, enterococci, and HF183 $\left(\mathrm{T}_{90}\right.$ and $\mathrm{T}_{99}$ values are the times required for $90 \%$ and $99 \%$ reduction, respectively). The $\mathrm{T}_{90}$ and $\mathrm{T}_{99}$ values for PMMoV could not be interpolated but are expected to be $>120$ days based on the data.

The persistence and decay of fecal bacteria in soils has also been previously studied (Jamieson et al., 2002; Vinten et al., 2002; Brennan et al., 2010b; Parsai et al., 2018), mostly in the context of manure or sewage sludge biosolid application to agricultural soils. Rogers et al. (2011) reported approximately $2-\log _{10}$ reduction of the GenBac3 qPCR gene target after 120 days in manure-amended soil at $25^{\circ} \mathrm{C}$. The data from their study showed a two-stage, first-order, and biphasic decay pattern, indicating a tailing effect starting at around 10 days, which is similar to the tailing shape of the curve of HF183 flushed away from soil in our study after different lengths of time. Underthun et al. (2018) was unable to detect $E$. coli in a sandy loam soil at $30{ }^{\circ} \mathrm{C}$ after 56 days when the concentration on day 1 was $10^{7} \mathrm{CFU} / \mathrm{g}$. Lang and Smith (2007) reported that the decay of $E$. coli in air-dried sandy loam at $15{ }^{\circ} \mathrm{C}$ was slower (with less than $1-\log _{10}$ reduction after 3 months) compared to moist sandy loam at the same temperature, where there was a $5-\log _{10}$ reduction of E. coli after 3 months. The choice to let our soil samples air dry after spiking with sewage may have led to slower decay of fecal bacteria in the time-delay flushing experiment. Decay of the viral and bacterial indicators in the soil is not directly measured in our study, as we did not measure microbial indicators in the soil, and therefore we cannot separate out the effects of decay vs. desorption. It is possible that fewer bacteria would have flushed away in our time-delay flushing experiment if the soil was not air dried. Nevertheless, our results do provide an indication of how long these different indicators can be expected to be detected in the interflow of polluted soils after a sewage spill event.

Previous studies of the decay of microbial source tracking markers have mainly evaluated persistence in water matrices and were nearly an order of magnitude faster than those we report for spiked soils that were allowed to dry. For instance, in a study of the persistence of $E$. coli and the HF183 marker in river water with $10 \mathrm{~g} / \mathrm{L}$ of river sediments, Dick et al. (2010) reported $\mathrm{T}_{99}$ values of 2.80 days for $E$. coli and 1.88 days for HF183. Liang et al. (2012) reported $99 \%$ decay of the HF183 marker in 2.7 days in river water at ambient temperature in a greenhouse at $15{ }^{\circ} \mathrm{C}$ (under natural light exposure), and Hamza et al. (2011) reported reductions of $1.1 \log _{10}$ at $25{ }^{\circ} \mathrm{C}$ and by $0.5 \log _{10}$ at $4{ }^{\circ} \mathrm{C}$ for the concentrations of $\mathrm{PMMoV}$ in river water after 21 days (under dark conditions). In sewage-inoculated sediments, ZimmerFaust et al. (2017) found substantially faster decay rates for HF183 compared to E. coli or enterococci, but PMMoV was not studied.

In the present study, the decay rate of the HF183 marker was found to be faster than that of PMMoV by about an order of magnitude, meaning that the PMMoV marker would likely persist longer than the HF183 marker in soil by about a factor of ten. This characteristic is a crucial aspect of the relationship between these two markers. Indeed, the persistence of PMMoV in groundwater was found by Morrison et al. (2020) to be an important characteristic to support its potential use in evaluating virus log reduction values. Due to their differing persistence, PMMoV has a greater capacity for accumulating within an environment, assuming sources of this marker into the environment are constant. In this sense, HF183 may be used to indicate more recent sources of contamination, while PMMoV may be a better conservative surrogate for older fecal contamination, which may contain enteric viruses that have higher persistence in the environment.

It should be noted that some of the previous studies left samples exposed to sunlight, which can increase the inactivation rate for bacteria and viruses, especially in a water matrix where sunlight interacts with dissolved compounds to form reactive 
intermediates (Nelson et al., 2018). Our experimental setup simulated only the below-ground portion of a sewage spill, for example, when a SSO infiltrates soils or when exfiltration from belowground sewer pipes occurs. This simulation constrained our experimental setup to dark, temperature-controlled conditions and was not meant to address the influences of diurnal or seasonal temperature changes, ultraviolet (UV) light or sunlight exposure, or native microorganisms present in both soil and water. These factors have been shown in the literature to reduce fecal indicator and host-associated genetic marker degradation, but mainly in water matrices (Bae and Wuertz, 2012; Korajkic et al., 2014; Korajkic et al., 2019). The soil used in our experiments was native riverbank soil, and while it was not autoclaved prior to the experiment, the soil was dried in a drying oven at $105{ }^{\circ} \mathrm{C}$ and sieved to remove larger debris, which may have affected the native microbial community in the soil. Therefore, there is still a need to better understand the persistence, under environmentally relevant conditions, of bacterial and viral markers in dry soils that are later flushed, such as in the vadose zone where sewer lines are typically located. In addition, performing experiments in centrifuge tubes likely hampered the natural processes of drainage and ventilation of soils. This limitation may have resulted in greater retention of microorganisms in the soil. Future experiments conducted in situ with lysimeters (as in Horswell et al., 2010) or using soilfilled columns for spiking (as in Nakamura et al., 2004 or Paredez et al., 2017) are recommended. Other limitations of this study are that the sewage used to spike the soils came from a single grab sample, which may not be characteristic of all sanitary sewer collection systems. Furthermore, the protocol used to flush soils may not be representative of actual in situ flow through the subsurface. Future experiments should compare flushing when alternative laboratory set-ups are used, such as soil columns.

Despite the limitations of this study and the need for future studies that evaluate persistence under the conditions mentioned above, our findings have important applications in soil and water quality monitoring. For example, consider a situation in which the presence of either of these markers (HF183 or PMMoV) in runoff water collected from a particular patch of soil is being used to assess potential wastewater contamination of the soil matrix. If the initial concentration of both HF183 and PMMoV is known in the suspected contaminant (for example, wastewater from surface sewer exfiltration or overflow), then the ratio of these markers in the runoff water can be used to roughly estimate the relative age of soil contamination events and to gain some clues about the origin of human fecal contamination (e.g., whether it is from a fresh source or an older source). In our study, the ratio of PMMoV:HF183 on day 1 was 1:100, whereas the same ratio on day 121 increased to $\sim 20: 1$; this change in persistence over time reflects the older age of our experimental soil contamination.

\section{Conclusions}

In this study, we simulated the decay and flushing of solutes, DOC and TDN, fecal indicators E. coli and enterococci (measured by culture-based methods), and microbial source tracking markers HF183 and PMMoV (measured via ddPCR and RT-ddPCR, respectively), from riverbank soils subjected to SSO events, sewer exfiltration, or other types of sewage contamination. The presence of molecular markers alone may be insufficient to substantiate a health risk; however, the differences in flushing rates and decay and sorption behaviors between both molecular and culture-based markers are nonetheless critical to consider fully. Flushing of both solutes (DOC and TDN) and microorganisms proceeded rapidly, with most solutes (90\%) and microorganisms (99\%) being removed from soil by the 5 th flush. Our decay experiments further demonstrated that E. coli, enterococci, HF183, and PMMoV could all be detected in flushes of sewage-spiked soils, even after 4 months of dry conditions. The contrasting decay rates we determined for viral and bacterial markers in dry soils, with PMMoV degrading 5-6 times more slowly in dry soils than bacteria, imply that PMMoV is a useful indicator of legacy sewage contamination in soils, whereas HF183 indicated more recent sources of contamination. If information on the concentrations HF183 and PMMoV in suspected contamination sources is known, then the ratio of PMMoV:HF183 could provide a valuable tool for evaluating the relative age of soil contamination events. Overall, our results suggest that sewage spills or leaks into soil can be long-term sources of microbial pollutants and that the 
decay of different microbial markers in the soil matrix is wide ranging.

\section{Supplementary Information}

Acknowledgements We acknowledge funding and support from the San Diego River Conservancy, California State Water Resources Control Board, Region 9, San Diego State University Division of Graduate Affairs, Office of Councilmember Scott Sherman (District 7) of the City of San Diego, Office of Councilmember Lori Zapf (District 2) of the City of San Diego, the William E. Leonhard Jr. Endowment, and the San Diego State University Summer Undergraduate Research Program. We thank M. Garcia, R. Becerra, H. Bertsch, and S. Chao for assistance with laboratory analyses. We thank H. Yu for guidance with experimental design and acquisition of supplies to complete the fecal indicator bacteria analyses.

Author Contribution Calderon, formal analysis, investigation, supervision, writing; Verbyla, conceptualization, formal analysis, funding acquisition, supervision, methodology, visualization, writing; Gil, formal analysis, investigation, writing; Pinongcos, formal analysis, investigation, supervision, writing; Kinoshita, funding acquisition, project administration, writing; Mladenov, conceptualization, formal analysis, funding acquisition, project administration, supervision, methodology, visualization, writing.

Data Availability Supplementary Information accompanies this article. The datasets generated during and analyzed during the current study are available from the corresponding author on reasonable request.

\section{Declarations}

Competing interests The authors declare no competing interests.

Open Access This article is licensed under a Creative Commons Attribution 4.0 International License, which permits use, sharing, adaptation, distribution and reproduction in any medium or format, as long as you give appropriate credit to the original author(s) and the source, provide a link to the Creative Commons licence, and indicate if changes were made. The images or other third party material in this article are included in the article's Creative Commons licence, unless indicated otherwise in a credit line to the material. If material is not included in the article's Creative Commons licence and your intended use is not permitted by statutory regulation or exceeds the permitted use, you will need to obtain permission directly from the copyright holder. To view a copy of this licence, visit http://creativecommons.org/licenses/by/4.0/.

\section{References}

Ahmed, W., Harwood, V. J., Gyawali, P., Sidhu, J. P. S., \& Toze, S. (2015). Comparison of concentration methods for quantitative detection of sewage-associated viral markers in environmental waters. Applied and Environment Microbiology, 81, 1743-1750. https://doi.org/10.1128/AEM. 03851-14.

Amick, R.S., Burgess, E.H., 2000. Exfiltration in sewer systems, US EPA. Cincinatti, OH.

Arnold, B. F., Schiff, K. C., Ercumen, A., Benjamin-Chung, J., Steele, J. A., Griffith, J. F., Steinberg, S. J., Smith, P., McGee, C. D., Wilson, R., Nelsen, C., Weisberg, S. B., \& Colford, J. M. (2017). Acute illness among surfers after exposure to seawater in dry-and wet-weather conditions. American Journal of Epidemiology, 186, 866-875. https:// doi.org/10.1093/aje/kwx019

American Society of Civil Engineers (ASCE) (2017). 2017 Infrastructure report card: A comprehensive assessment of America's infrastructure (pp. 110). American Society of Civil Engineers. https://doi.org/10.5194/tc-6-675-2012

Aschmann, H. (1973). Distribution and peculiarity of Mediterranean ecosystems. In Mediterranean type ecosystems (pp. 11-19). Springer, Berlin, Heidelberg.

Astaraie-Imani, M., Kapelan, Z., Fu, G., \& Butler, D. (2012). Assessing the combined effects of urbanisation and climate change on the river water quality in an integrated urban wastewater system in the UK. Journal of Environmental Management, 112, 1-9. https://doi.org/10.1016/j. jenvman.2012.06.039

Baresel, C., Olshammar, M., 2019. On the importance of sanitary sewer overflow on the total discharge of microplastics from sewage water. Journal of Environmental Protection. (Irvine,. Calif). 10, 1105-1118. https://doi.org/10.4236/ jep.2019.109065

Beaudoin, A. (2003). A comparison of two methods for estimating the organic content of sediments. Journal of Paleolimnology, 29, 387-390. https://doi.org/10.1023/A: 1023972116573

Bivins, A., Crank, K., Greaves, J., North, D., Wu, Z., \& Bibby, K. (2020). Cross-assembly phage and pepper mild mottle virus as viral water quality monitoring tools-potential, research gaps, and way forward. Current Opinion in Environmental Science \& Health, 16, 54-61.

Bradbury, K. R., Borchardt, M. A., Gotkowitz, M., Spencer, S. K., Zhu, J., \& Hunt, R. J. (2013). Source and transport of human enteric viruses in deep municipal water supply wells. Environmental Science and Technology, 47, 40964103. https://doi.org/10.1021/es400509b

Brennan, F. P., Abram, F., Chinalia, F. A., Richards, K. G., \& O'Flaherty, V. (2010a). Characterization of environmentally persistent Escherichia coli isolates leached from an Irish soilv. Applied and Environment Microbiology, 76, 2175-2180. https://doi.org/10.1128/AEM.01944-09

Brennan, F. P., O'Flaherty, V., Kramers, G., Grant, J., \& Richards, K. G. (2010b). Long-term persistence and leaching of Escherichia coli in temperate maritime soils. Applied and Environment Microbiology, 76, 1449-1455. https:// doi.org/10.1128/AEM.02335-09 
California State Water Resources Control Board, 2015. Plan and assess: Sewage spills [WWW Document]. Calif. Water Boards' Annu. Perform. Rep. - Fisc. Year 201415. https://www.waterboards.ca.gov/about_us/perfo rmance_report_1415/plan_assess/12411_sso_sewage_volume.shtml (accessed 5.13.20).

Chisala, B. N., \& Lerner, D. N. (2008, December). Distribution of sewer exfiltration to urban groundwater. In Proceedings of the Institution of Civil Engineers-Water Management (Vol. 161, No. 6, pp. 333-341). Thomas Telford Ltd.

Day, C.A., Seay, G., 2020. Impacts of storm characteristics on generating sanitary sewer overflow (SSO) events for an urban sewershed. Pap. Appl. Geogr. 0, 1-11https://doi. org/10.1080/23754931.2020.1755886

Dick, L.K., Stelzer, E.A., Bertke, E.E., Fong, D.L., Stoeckel, D.M., 2010. Relative decay of bacteroidales microbial source tracking markers and cultivated Escherichia coli in freshwater microcosms. Applied and Environmental Microbiology. 76, 3255\{ \textendash\}3262. https://doi.org/ 10.1128/AEM.02636-09

Gotkowitz, M. B., Bradbury, K. R., Borchardt, M. A., Zhu, J., \& Spencer, S. K. (2016). Effects of climate and sewer condition on virus transport to groundwater. Environmental Science and Technology, 50, 8497-8504. https://doi. org/10.1021/acs.est.6b01422

Hamza, I. A., Jurzik, L., Uberla, K., \& Wilhelm, M. (2011). Methods to detect infectious human enteric viruses in environmental water samples. International Journal of Hygiene and Environmental Health, 214, 424-436. https://doi.org/10.1016/j.ijheh.2011.07.014

Hathaway, J. M., \& Hunt, W. F. (2011). Evaluation of first flush for indicator bacteria and total suspended solids in urban stormwater runoff. Water, Air, and Soil Pollution, 217, 135-147. https://doi.org/10.1007/s11270-010-0574-y

Henry, L., Dillaha, T.A. (2004). Development of isotherm equations for partitioning between soil-adsorbed and planktonic Escherichia coli, in: Proceedings from the 2004 American Society of Agricultural and Biological Engineers Annual Meeting, Ottawa, Canada August 1 - 4, 2004, https://doi.org/10.13031/2013.16202

Horswell, J., Hewitt, J., Prosser, J., Van Schaik, A., Croucher, D., Macdonald, C., ... \& Speir, T. (2010). Mobility and survival of Salmonella Typhimurium and human adenovirus from spiked sewage sludge applied to soil columns. Journal of Applied Microbiology, 108(1), 104-114.

Huggett, J. F., Foy, C. A., Benes, V., Emslie, K., Garson, J. A., Haynes, R., Hellemans, J., Kubista, M., Mueller, R. D., Nolan, T., Pfaffl, M. W., Shipley, G. L., Vandesompele, J., Wittwer, C. T., \& Bustin, S. A. (2013). The digital MIQE guidelines: Minimum information for publication of quantitative digital PCR experiments. Clinical Chemistry, 59, 892-902. https://doi.org/10.1373/clinchem.2013.206375

Hunt, R. J., \& Johnson, W. P. (2017). Pathogen transport in groundwater systems: Contrasts with traditional solute transport. Hydrogeology Journal, 25(4), 921-930.

Jagai, J. S., DeFlorio-Barker, S., Lin, C. J., Hilborn, E. D., \& Wade, T. J. (2017). Sanitary sewer overflows and emergency room visits for gastrointestinal illness: Analysis of Massachusetts data, 2006-2007. Environmental Health Perspectives, 125, 129003. https://doi.org/10.1289/EHP20 48
Jamieson, R. C., Gordon, R. J., Sharples, K. E., Stratton, G. W., \& Madani, A. (2002). Movement and persistence of fecal bacteria in agricultural soils and subsurface drainage water: A review. Canadian Biosystems Engineering, 44(1), 1-9.

Julian, T. R., Islam, M. A., Pickering, A. J., Roy, S., Fuhrmeister, E. R., Ercumen, A., Harris, A., Bishai, J., \& Schwab, K. J. (2015). Genotypic and phenotypic characterization of Escherichia coli isolates from feces, hands, and soils in rural Bangladesh via the Colilert Quanti-Tray System. Applied and Environmental Microbiology, 81(5), 1735-1743.

Lang, N. L., \& Smith, S. R. (2007). Influence of soil type, moisture content and biosolids application on the fate of Escherichia coli in agricultural soil under controlled laboratory conditions. Journal of Applied Microbiology, 103(6), 2122-2131. https://doi.org/10.1111/j.1365-2672. 2007.03490.x

Liang, Z., He, Z., Zhou, X., Powell, C. A., Yang, Y., Roberts, M. G., \& Stoffella, P. J. (2012). High diversity and differential persistence of fecal Bacteroidales population spiked into freshwater microcosm. Water Research, 46, 247-257. https://doi.org/10.1016/j.watres.2011.11.004

Mahaut, V., \& Andrieu, H. (2019). Relative influence of urbandevelopment strategies and water management on mixed (separated and combined) sewer overflows in the context of climate change and population growth: A case study in Nantes. Sustainable Cities and Society, 44, 171-182. https://doi.org/10.1016/j.scs.2018.09.012

Morrison, C. M., Betancourt, W. Q., Quintanar, D. R., Lopez, G. U., Pepper, I. L., \& Gerba, C. P. (2020). Potential indicators of virus transport and removal during soil aquifer treatment of treated wastewater effluent. Water Research, 177,115812 .

Nakamura, K., Harter, T., Hirono, Y., Horino, H., \& Mitsuno, T. (2004). Assessment of root zone nitrogen leaching as affected by irrigation and nutrient management practices. Vadose Zone Journal, 3(4), 1353-1366.

Paredez, J. M., Mladenov, N., Galkaduwa, M. B., Hettiarachchi, G. M., Kluitenberg, G. J., \& Hutchinson, S. L. (2017). A soil column study to evaluate treatment of trace elements from saline industrial wastewater. Water Science and Technology, 76(10), 2698-2709.

Parsai, T., Wier, M.H., Miller, A., Gurian, P.L., Kumar, A., 2018. The persistence of pathogens in biosolids-amended soil: Knowns, unknowns and future directions, in: Rose, J.B., Jiménez-Cisneros, B. (Eds.), Sanitation and disease in the 21st century: health and microbiological aspects of excreta and wastewater management. Michigan State University, UNESCO, E. Lansing, MI, USA. https://doi.org/ 10.14321/waterpathogens.52

Potera, C. (2018). From one set of pipes to another: Gastrointestinal illness following sanitary sewer overflows. Environmental Health Perspectives, 126, 044001-1-044001-2. https://doi.org/10.1289/EHP3225

Reynolds, J. H., \& Barrett, M. H. (2003). A review of the effects of sewer leakage on groundwater quality. Water and Environment Journal, 17(1), 34-39.

Rogers, S. W., Donnelly, M., Peed, L., Kelty, C. A., Mondal, S., Zhong, Z., \& Shanks, O. C. (2011). Decay of bacterial pathogens, fecal indicators, and real-time quantitative 
PCR genetic markers in manure-amended soils. Applied and Environmental Microbiology, 77(14), 4839-4848. https://doi.org/10.1128/AEM.02427-10

Rutsch, M., Rieckermann, J., Cullmann, J., Ellis, J. B., Vollertsen, J., \& Krebs, P. (2008). Towards a better understanding of sewer exfiltration. Water Research, 42(10-11), 2385-2394.

San Diego Regional Water Quality Control Board. (2019). Investigative order No. R9-2019-0014. San Diego, CA, USA.

Schiff, K., Griffith, J., Steele, J., Arnold, B., Ercumen, A., Benjamin-Chung, J., Colford, J.M., Soller, J., Wilson, R., Mcgee, C., 2016. The surfer health study a three-year study examining illness rates associated with surfing during wet weather. SCCWRP.

Schijven, J., Pang, L., Ying, G.G., 2017. Evaluation of subsurface microbial transport using microbial indicators, surrogates and tracers, in: Rose, J.B., Jiménez-Cisneros, B. (Eds.), Sanitation and disease in the 21st century: health and microbiological aspects of excreta and wastewater management. Global Water Pathogen Project, Michigan State University, UNESCO, East Lansing, MI, USA. https://doi.org/10.14321/waterpathogens.10

Smith, E. J., Davison, W., \& Hamilton-Taylor, J. (2002). Methods for preparing synthetic freshwaters. Water Research, 36, 1286-1296. https://doi.org/10.1016/S0043-1354(01) $00341-4$

Stevik, T. K., Aa, K., Ausland, G., \& Hanssen, J. F. (2004). Retention and removal of pathogenic bacteria in wastewater percolating through porous media: A review. Water Research, 38(6), 1355-1367.

Symonds, E. M., Nguyen, K. H., Harwood, V. J., \& Breitbart, M. (2018). Pepper mild mottle virus: A plant pathogen with a greater purpose in (waste)water treatment development and public health management. Water Research, 144, 1-12. https://doi.org/10.1016/j.watres.2018.06.066

Symonds, E.M., Verbyla, M.E., Lukasik, J.O., Kafle, R.C., Breitbart, M., Mihelcic, J.R., 2014. A case study of enteric virus removal and insights into the associated risk of water reuse for two wastewater treatment pond systems in Bolivia. Water Research 65https://doi.org/10.1016/j. watres.2014.07.032

Tavakol-Davani, H., Goharian, E., Hansen, C. H., TavakolDavani, H., Apul, D., \& Burian, S. J. (2016). How does climate change affect combined sewer overflow in a system benefiting from rainwater harvesting systems? Sustainable Cities and Society, 27, 430-438. https://doi.org/ 10.1016/j.scs.2016.07.003

Underthun, K., De, J., Gutierrez, A., Silverberg, R., \& Schneider, K. R. (2018). Survival of Salmonella and Escherichia coli in two different soil types at various moisture levels and temperatures. Journal of Food Protection, 81(1), 150157. https://doi.org/10.4315/0362-028X.JFP-17-226

US EPA, 2019. Method 1696: Characterization of human fecal pollution in water by HF183/BacR287 TaqMan® quantitative polymerase chain reaction (qPCR) Assay. Cincinatti, $\mathrm{OH}$.

US EPA, 1989. Results of the evaluation of groundwater impacts of sewer exfiltration. Cincinatti, $\mathrm{OH}$.

Verbyla, M.E., Symonds, E.M., Kafle, R.C., Cairns, M.R., Iriarte, M., Mercado Guzmán, A., Coronado, O., Breitbart, M., Ledo, C., Mihelcic, J.R., 2016. Managing microbial risks from indirect wastewater reuse for irrigation in urbanizing watersheds. Environmental Science and Technology 50https://doi.org/10.1021/acs.est.5b05398

Vinten A.J.A.*, Lewis, D.R., Fenlon, D.R., Leach, K.A., Howard, R., Svoboda, I., Ogden, I., 2002. Fate of Escherichia coli and Escherichia coli O157 in soils and drainage water following cattle slurry application at 3 sites in southern Scotland. Soil Use and Management 18, 223-231https:// doi.org/10.1079/sum2002114

Watanabe, R., Harada, H., Yasui, H., Le, T. Van, Fujii, S., 2019. Exfiltration and infiltration effect on sewage flow and quality: a case study of Hue, Vietnam. Environment Technology (United Kingdom) 0, 1-11https://doi.org/10. 1080/09593330.2019.1680739

Zimmer-Faust, A. G., Thulsiraj, V., Marambio-Jones, C., Cao, Y., Griffith, J. F., Holden, P. A., \& Jay, J. A. (2017). Effect of freshwater sediment characteristics on the persistence of fecal indicator bacteria and genetic markers within a Southern California watershed. Water Research, 119, 1-11.

Publisher's Note Springer Nature remains neutral with regard to jurisdictional claims in published maps and institutional affiliations. 